Article

\title{
Minimization of Power Losses through Optimal Battery Placement in a Distributed Network with High Penetration of Photovoltaics
}

\author{
Ahmed Alzahrani ${ }^{1, *}$, Hussain Alharthi ${ }^{1}$ and Muhammad Khalid ${ }^{1,2}$ (D) \\ 1 Electrical Engineering Department, King Fahd University of Petroleum and Minerals, Dhahran 31261, \\ Saudi Arabia; haharthi@ieee.org (H.A); mkhalid@kfupm.edu.sa (M.K.) \\ 2 K.A.CARE Energy Research \& Innovation Center, Dhahran 31261, Saudi Arabia \\ * Correspondence: eng.a.zahrani@gmail.com; Tel.: +966-56-710-0085
}

Received: 19 November 2019; Accepted: 23 December 2019; Published: 27 December 2019

check for updates

\begin{abstract}
The problems associated with the deployment of intermittent, unpredictable and uncontrollable solar photovoltaics (PV) can be feasibly solved with battery energy storage systems (BESS), particularly in terms of optimizing the available capacity, increasing reliability and reducing system losses. Consequently, the degree of importance of BESS increases in proportion to the level of PV penetration. Nevertheless, the respective high cost of BESS imposes a huge concern and the need to establish a techno-economic solution. In this paper, we investigate the system losses and power quality issues associated with the high deployment of PV in a grid network and hence formulate BESS capacity optimization and placement methodology based on a genetic algorithm. The concept of the proposed methodology has been tested and validated on a standard IEEE 33 bus system. A brief stepwise analysis is presented to demonstrate the effectiveness and robustness of the proposed methodology in reducing the incremental system losses experienced with increased PV penetration. Furthermore, based on the proposed optimization objectives, a comparative study has also been performed to quantify the impact and effectiveness of aggregated and distributed placement of BESS. The results obtained exhibit a substantial reduction in system losses, particularly in the case of distributed BESS placement.
\end{abstract}

Keywords: battery energy storage system; distribution network; renewable energy sources

\section{Introduction}

Today, nations all around the globe are progressing towards a cleaner environment. Over the years, the accumulation of several factors consequently brought about the unprecedented requirement for renewable energy resources (RES) as a possible integration to power networks [1,2]. The conceptual installation of RESs as distributed energy resources (DER) in a grid network has been established to provide advantages such as independency from exhaustible/dwindling carbon-based generations, meet the ever-increasing electric power demand, eco-friendly power generation and option for load side generation that mitigates the need for grid expansion to a certain extent [3]. However, most of the matured potential RES technologies such as solar (PV) and wind energy sources, possess a threat not only to power quality of the power network but also limits their economic significance [4], due to their transient power generation characteristics that explicitly impacts the reliability and power quality of the grid [5].

Accordingly, the realization of smart grids has been postulated and promoted to establish and optimally operate distributed networks more effectively and economically [6]. The installation rooftop PV installation is a contemporary form of distributed generation wherein customers are equipped with 
generation and selling of electric power as well, forming a bi-directional power flow from conventional load buses [7]. Consequently, this type of decentralized power generation will explicitly limit the controllability of power flow and as a result, the system will be vulnerable to voltage violation and other power quality issues [8]. Henceforth, the concept of an energy storage system (ESS) has been adopted to provide ancillary support for optimal generation, transmission and demand side management [9-11].

Several research works have addressed the challenges associated with RES penetration to mitigate the drawback of the uncertainty nature [12-17]. Nowadays, many distribution networks encounter significant challenges and dramatic transformation toward a new structure led by correlated factors. This includes demand-side management, power quality standards, RES deployment, and reliability requirements [12]. The ancillary services provided by ESS is not just limited to overcome the fluctuant nature RES but can also be applicative for voltage regulation, enhancement of power quality $[13,14]$, smoothing RES power generation, scheduling of optimal power generation dispatch and RES operational flexibility [15-17].

Nevertheless, an optimal placement of ESS is an important system planning process for its effective and economical utilization [18]. This is particularly true in the case of distribution networks, where the ESS is installed to explicitly or implicitly provide ancillary services such as voltage regulation, frequency support, increase reliability, mitigate peak demand, reduce RES congestion or reduce transmission and overall system losses [19]. Recent review research in [20,21] highlights the importance of optimizing the location of ESSs in power system networks from energy supply chain point of view. Allocating ESSs needs to have a model that considers network constraints [22]. However, the targeted model is complicated which in turn reduces researches interest in ESSs allocation problem.

The formulation of an optimal ESS sitting that is efficient and effectively feasible is still a challenging problem, especially for a large-scale system [23]. Many researchers have postulated numerous propositions for techno-economic sizing and sitting of ESS in power systems networks [24]. The authors in [25] have proposed operational models that incorporate ESSs with DERs to mitigate the financial risks on the electricity market and to avoid some functional limitations such as mono-directional energy flow. Moreover, wind energy integration has been introduced and analyzed in the presence of ESSs; the outcomes showed that ESS would diminish the wind power drawbacks such as wind fluctuation and excessive power. Further, the conducted work includes a cost comparison that is based on a case study using the IEEE 15-bus system, which shows that lithium-ion batteries are not economically competitive compared to lead-acid batteries.

Furthermore, the application of ESS can also be extended for Energy Management Peak Shaving (EM-PS), beneficial to obviate and mitigate high electricity prices during peak loading hours [26]. In similar terms, the transmission losses incured by the utility grid can also be reduced with appropriate ESS utilization, presented in [27]. In this study, the author proposes an ESS capacity optimization and placement based on meta heuristic harmony search algorithm for mitigation of overall system loss. The decrement in utlity power supply and its associated losses has been validated and presented using a modified IEEE 37 bus system integrated with RES microgrid (MG). The research study in [4] aims to maximize the investment cost by optimizing the location in the micro-grid (MG). A novel approach using a matrix real-coded Genetic Algorithms (GA) algorithm is proposed. Two different cases have been studied; case one is done using a Lead-Acid battery while the second case is done using Vanadium Redox battery, which recommended as a more economical choice than a lead-acid battery. The researchers in [28] introduced a hybrid technique to solve the intermittency problem of wind power and reducing the total cost. The proposed hybrid technique utilizes the advantage of artificial intelligence (AI), particularly neural network (NN) concept, to forecast the wind generated power in Madison city, meanwhile using particle swarm optimization (PSO) algorithm to find the optimal location of BESS in the transmission network.

The study in $[28,29]$ aims to reduce the total cost and maintain the power quality of the grid integrated with wind generation farms through the deployment of different ESS technologies. This work investigates numerous mathematical frameworks to formulate an optimal ESS placement. From 
this study, the authors posit that, apart from a sustainable utilization of wind power output, the rated capacity of ESS is highly dependent on the degree of penetration as well as the location RES based DG with respect to the utility grid. In addition, distinct capacity is required for different types of ESS, explicitly due to their efficiency. In [30], an optimal ESS allocation strategy has been proposed using GA and further its impact on the performance enhancement of distribution networks (DN) has been comprehensively discussed. Using the same optimization framework, the study in [31] proposes the implementation of ESS for total cost reduction and voltage regulation. However, both these studies did not consider the impact of RES penetration and its effect on DN. A recent attempt in [17] aims to discretize and develop a model of wind distribution using Clayton-Copula method. The two proposed methods have been integrated with multi-objective PSO to form a practical approach to minimize the total cost and find the optimal location and capacity of ESS while considering the uncertainties of wind. The proposed approach tested on the IEEE 57-bus system, which shows improved outputs aligned with the authors' goals.

Numerous researches address different types of challenges associated with DN and proposed ESS as a potential solution as discussed in the aforementioned literature. The most common and beneficial utilization of ESS can be in the process of load levelling. Considering the relationship of system losses with the related squared current, load shifting from peak to off-peak time will result in a significant reduction of power losses. This is achieved efficiently as well as economically with optimal strategic placement of ESS. In this paper, an optimal BESS allocation strategy is formulated to reduce overall system losses in a DN with high PV penetration. The strategy is based on GA optimization technique. The study involves an in-depth illustrative investigation of the impact that high PV penetration has on system losses in a DN. The proposed technique is tested and validated on IEEE 33 bus system. Furthermore, a quantitative based comparative study is presented between aggregated and distributed deployment of BESS to outline their potential impact and contribution towards the reduction of system losses.

The remainder of this paper is structured as follows: A detailed descriptive problem formulation is discussed in Section 2. Section 3 presents the proposed optimization concept and its mathematical model. Finally, the results and discussions are presented in Section 4, and the conclusion is given in Section 5 .

\section{Problem Description}

A simplified design of the distribution system with PV and BESS is presented in Figure 1. In this study, three main models are integrated with the distribution system, which are photovoltaic systems, and battery energy storage systems and loads. 


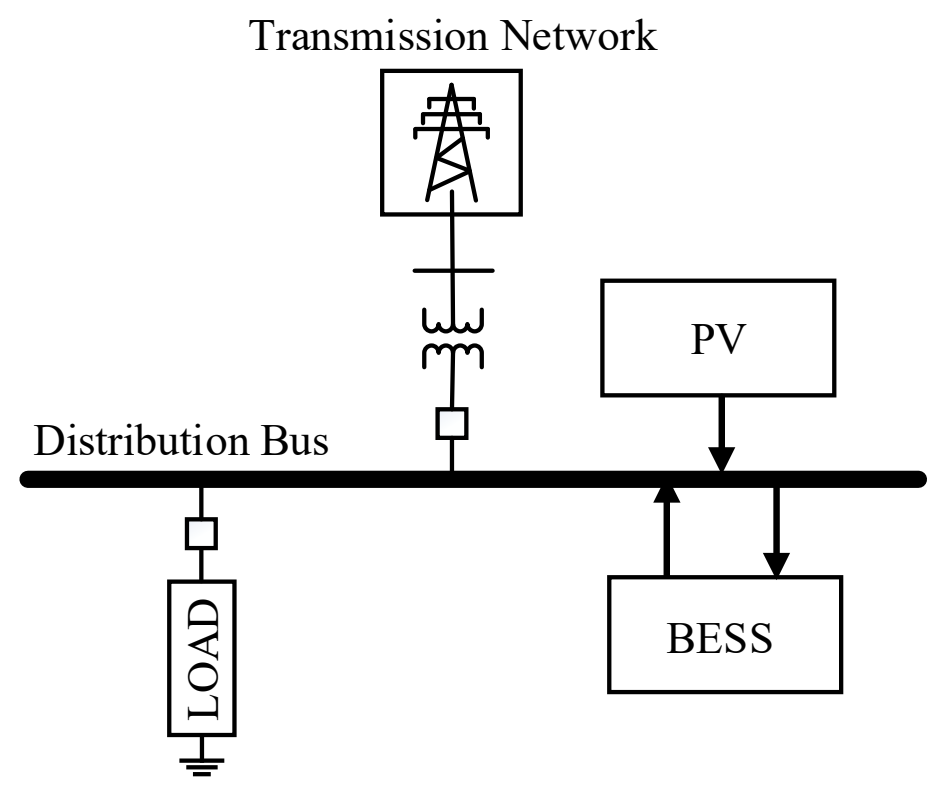

Figure 1. A typical structure of distribution networks (DN) with photovoltaics (PV) and battery energy storage systems (BESS).

The increase installations of PV systems in the DNs have transformed the flow of electrical power to be more of a bidirectional flow instead of a fixed direction as the case of a radial configuration [32]. Although this transformation of electrical power flow is beneficial from a technical and financial point of view, it also brings in a few technical challenges. One of the key challenges of utilizing solar PV systems is the uncertainty nature, which directly affects the system balance between demand and generated power. In such cases, the use of BESS is widely accepted as a feasible solution to provide or store electrical power as required [33]. The placement of solar PV systems and BESSs at demand centers helps in reducing the current flow in DN; hence, energy losses are minimized. Nevertheless, the appropriate allocation of BESS into DN also has the potential to significantly further decrease the DN power losses. The aim of this paper is to find the optimal placement of BESS to mitigate the power losses using GA as an optimization technique. In order to exemplify the distribution network properly, the IEEE 33-Bus system was utilized as shown in Figure 2.

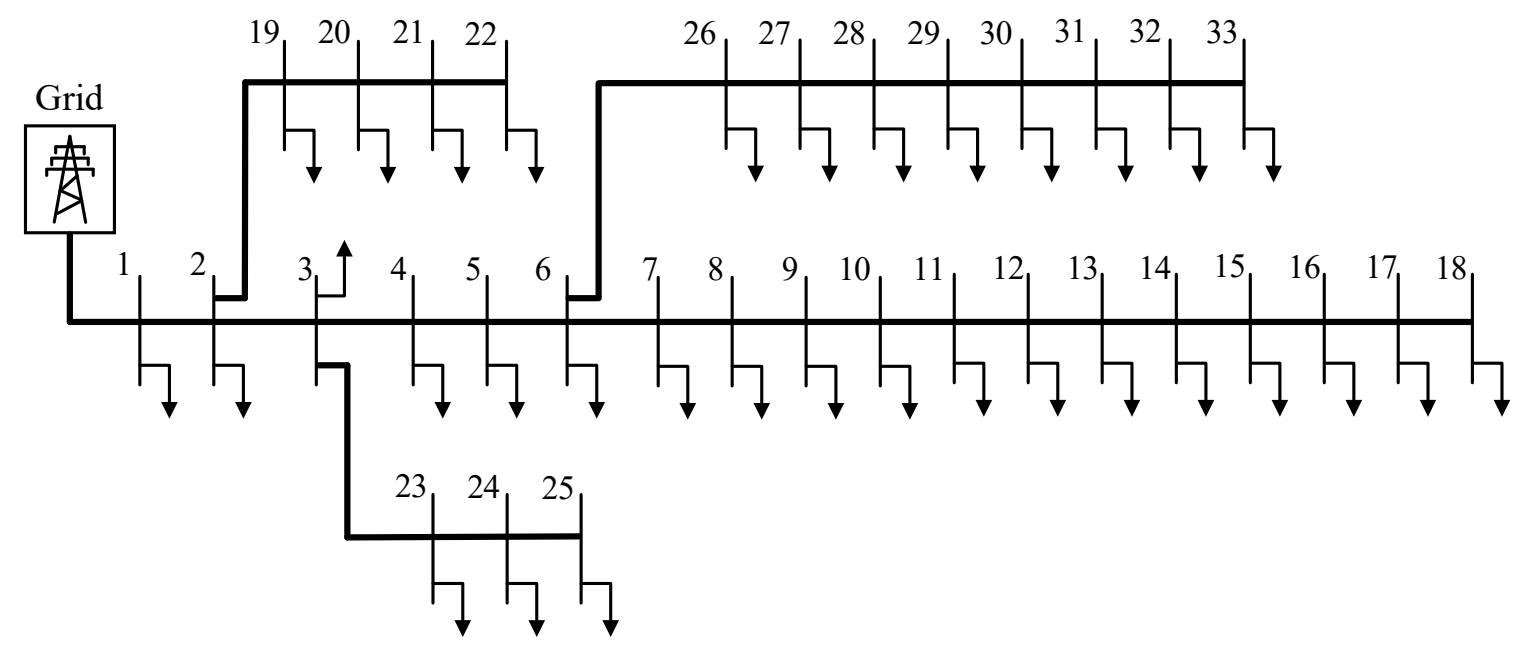

Figure 2. IEEE 33-Bus Distribution System [33].

As can be seen, the 33-Bus system is linked with 32 distribution lines, which has a power base of $10 \mathrm{MVA}$ and $12.66 \mathrm{kV}$ as a rated voltage. In addition, the active power and reactive power of the system load are 7.4 MW and 4.6 MVAR, respectively [28]. The power grid is mainly supplying the required 
demand. In this study, the optimal allocation of PV systems is not considered, since its contribution toward power losses reduction as well as load leveling is less effective compared to BESS optimal allocation. Therefore, six PV systems each one is sized as $1.6 \mathrm{~kW}$, which are installed arbitrary at six different $\mathrm{DN}$ buses utilized to supply active power.

The objective function is to minimize the power losses in the DN, which represented as follows:

$$
F_{\text {Loss }}=\operatorname{Min} \sum_{\Delta t=1}^{t_{\text {total }}} \sum_{i, j=1, i \neq j}^{n_{t}} G_{i, j}\left(V_{i}^{2}+V_{j}^{2}-2 V_{i} V_{j} \cos \left(\theta_{i}-\theta_{j}\right)\right)
$$

The considered time interval is $\Delta_{t}$, where $t_{\text {total }}$ is the total time period considered. The $G_{i, j}$ is the conductance between buses $i$ and $j$. The $n_{t}$ is total number of branches of the network. The voltage magnitudes of buses $i$ and $j$ are $V_{i}$ and $V_{j}$, where the voltage angles of buses $i$ and $j$ are $\theta_{i}$ and $\theta_{j}$.

Subjected to the following constraints

$$
\begin{gathered}
V_{i_{\text {min }}} \leq V_{i} \leq V_{i_{\text {max }}} \\
S_{b} \leq S_{b}^{\max }
\end{gathered}
$$

The minimum voltage magnitude for $i$ buses is $V_{i_{\min }}$, whereas the maximum voltage magnitude for $i$ buses is $V_{i_{\max }}$. The $S_{b}$ is the actual power flow, and the maximum actual power flow is $S_{b}{ }^{\max }$.

\section{Proposed Methodology}

The proposed methodology contains three main sub-sections, which are system modeling, BESS modeling, and the description of GA as an optimization technique. The comprehensive mathematical system modeling of the considered portion of the DN in this study is described in the following subsections followed by the utilized optimization approach to specify the optimal locations of the energy storage systems assuring the minimum power losses in the $\mathrm{DN}$.

\subsection{System Modeling}

The system model considered in this paper has two main models, which are the load model and solar photovoltaic model.

The first part is the load modeling, which is used to demonstrate typical loads in a distribution network. Generally, the electrical power is transmitted to load centers via distribution buses, which are fed from a power source network. In the IEEE 33-bus power system considered in this study, the area load has to be simplified and scaled to suit the testing model. In the proposed model, all parameters are estimated using online training based on real-time measurements to ensure that the model parameters are kept up to date to track the time-varying loads. In this paper, the power flow Forward-Backward Sweep (FBS) algorithm is used. Through the use of typical load profile, scaled values are utilized to generate 24 hours demands at each bus of the IEEE-33 bus system [33].

The second part is the solar PV model, which expresses the PV generation plant behavior throughout the day. There are several factors that affect the PV model such as rated power, solar irradiance, and temperature. Moreover, the PV model can be represented and simplified as shown in Figure 3. 


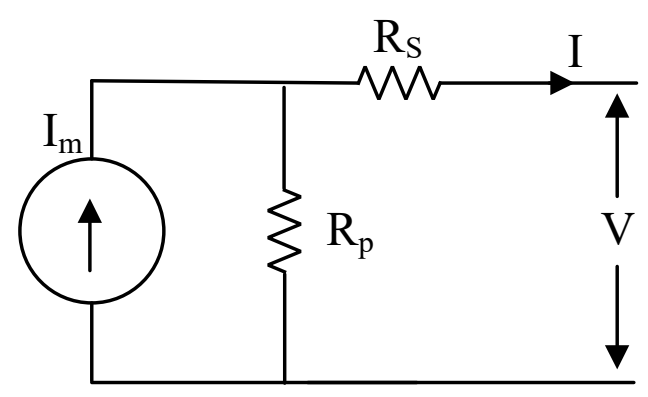

Figure 3. A simplified PV Model.

The PV array model consists of series and parallel resistances $R_{s}$ and $R_{p}$, series and parallel modules $N_{s}$ and $N_{p}$, the output voltage and current $V$ and $I$, and the module current source $I_{\mathrm{m}}$.

The current source of the module $I_{\mathrm{m}}$ can be expressed as follows:

$$
I_{\mathrm{m}}=I_{p v} N_{p}-I_{o} N_{p}\left[\exp \left(\frac{V+R_{s}\left(\frac{N_{s}}{N_{p}}\right) I}{V_{t} a N_{s}}\right)-1\right]
$$

The array thermal voltage $V_{t}$, and the ideality constant of the diode $a$.

The thermal voltage $V_{t}$ can be represented as follows:

$$
V_{t}=\frac{N_{c s} k T}{q}
$$

where, $N_{C S}$ is the number of series cells and $a$ is the Boltzmann's constant. The electron charge is $q$ and $T$ is the Kelvin temperature of the P-N junction.

The PV and reverse leakage currents $I_{p v}$ and $I_{o}$ can be represented as in the following equations:

$$
\begin{aligned}
& I_{p v}=\left(I_{p v n}+K_{i} \Delta T\right) \frac{G}{G_{n}} \\
& I_{0}=\frac{I_{s c n}+K_{i} \Delta T}{\exp \left(\frac{V_{o c n}+K_{v} \Delta T}{V_{t} a}\right)-1}
\end{aligned}
$$

The PV nominal current is $I_{p v n}$, and the temperature confident current and voltage are $K_{i}$ and $K_{v}$ respectively. The $G$ and $G_{n}$ represent the irradiance and the irradiance at nominal conditions, respectively. The nominal short circuit current is $I_{s c n}$ and the nominal open circuit voltage is $V_{o c n}$. Finally, the $\Delta T$ is the difference between the actual and the nominal Kelvin temperatures.

Apparently, the PV generates power in the daytime. The output power of the actual single PV module is presented in Figure 4. It is generated based on Dammam city solar irradiance which is measured in June of 2019. The maximum PV module output power is about $190 \mathrm{~W}$ at 12:00. 


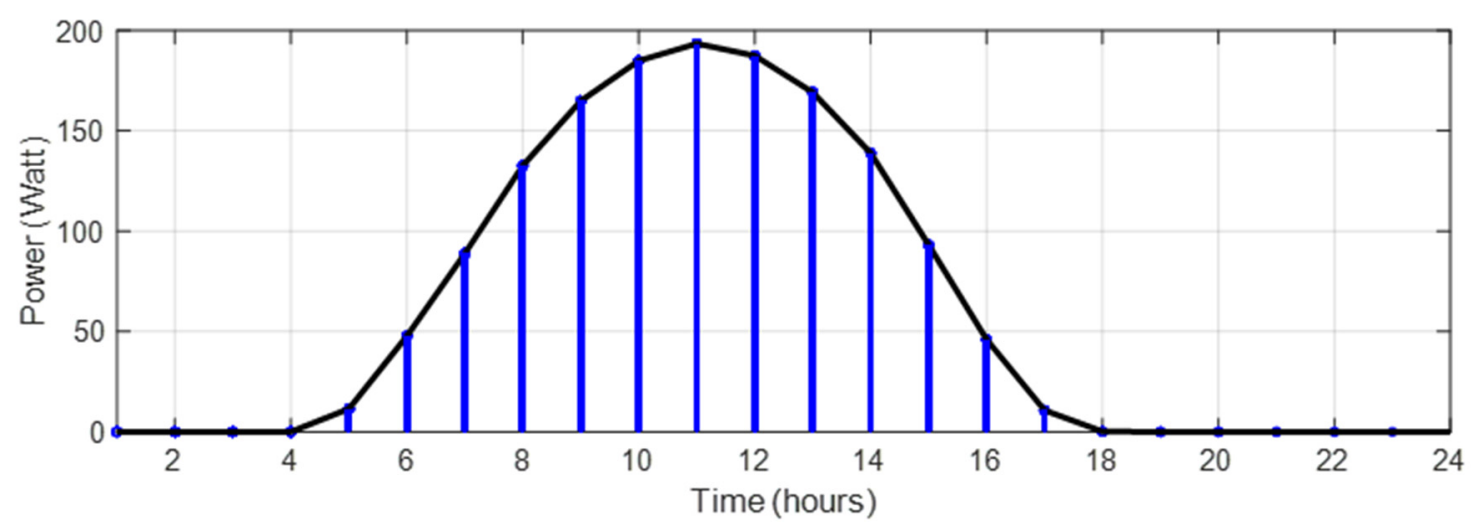

Figure 4. Real single PV module output power.

\subsection{BESS Modelling}

The model of the BESS includes the capacity of power charging and discharging, the energy capacity, and the efficiency of charging and discharging [6]. Practically, the BESS model is a nonlinear model due to the difference between charging and discharging efficiency values. Thus, in this study, both charging and discharging efficiency values are considered to be identical in order to linearize the BESS model.

The BESS model can be expressed as in the following equation:

$$
x(t+1)=\left\{\begin{array}{lll}
x(t)+\eta_{c} P_{s}(t) \Delta t & \forall & \left(P_{s}(t) \geq 0\right) \\
x(t)-\frac{1}{\eta_{d}} P_{s}(t) \Delta t & \forall & \left(P_{S}(t) \leq 0\right)
\end{array}\right.
$$

Subjected to the following constrains:

$$
\begin{gathered}
P_{S}^{\min }(t) \leq P_{s} \leq P_{S}^{\max }(t) \\
x^{\min }(t) \leq x \leq x_{s}^{\max }(t) .
\end{gathered}
$$

The storage level is $x$, and the amount of stored or supplied power is $P_{s}$. The charging and discharging efficiencies are $\eta_{c}$ and $\eta_{d}$, respectively.

The main application of this study is the load leveling using the BESS to minimize the DN power losses. The basic principle of load leveling is to reduce load variation throughout the day. The load variation reduction could be achieved by increasing the generation amount during off-peak periods and store it to supply the demand during peak periods. Several utilities are challenged by the difference between low and high demand levels. Thus, the load leveling helps to maximize the revenue sale from the off-peak generated power during the peak demand times and reduce the need to operate generation units with low efficiency [34,35]. Furthermore, the traditional power systems generation and loads arrangement lead to significant total power losses. One of the promising solutions to avoid power losses is the load leveling to maintain a reasonable load variant [36]. The adoption of BESS provides extra power dispatch elasticity and enables load leveling for longer periods. Usually, the BESS effectiveness in reducing power losses is subjected to the location, numbers and sizes of BESS used in the power system network [37]. Therefore, the optimal BESS placement is needed to further reduce the power losses. The stochastic optimization GA is utilized in this study to find the optimal BESS placement in DN.

\subsection{Genetic Algorithm}

The optimal solutions of the latest sophisticated problems are achieved using evolutionary optimization algorithms like the GA, Tabu search (TS), differential evolution (DE), and particle swarm (PS) [38]. Genetic Algorithms (GA) are well known evolutionary approaches which commonly 
employed to find the optimal solutions of the non-linear problems. These algorithms are stochastic searching algorithms that start with the initial population and process it through many iterations to find the optimal solution. It is uniquely simple, robust and known as a quick conversing method [39].

Generally, the GA formulation contains many elementary optimization parameters and operations such as generation $(G)$, population size, objective function, selection, crossover parameter and probability, and mutation parameter and probability, which require a specific setting depending on the intended optimization problem [40]. They affect the GA output accuracy and processing duration. Hence, they should be chosen precisely. The main GA operations to generate a new population $\left(P_{\text {new }}\right)$ of possible solutions $\left(X_{i}\right)$ are the crossover and mutation. These operations are controlled by crossover and mutation probabilities $(\alpha, \mu)$. The crossover is the next operation after the selection operation, where two random possible solutions $\left(X_{m}, X_{n}\right)$ are selected from the current generation $\left(G_{k}\right)$. The possible solution has an upper limit $\left(X^{\max }\right)$ and a lower limit $\left(X^{\min }\right)$. The goal of the crossover operation is to generate two new solutions $\left(X_{m d}, X_{n d}\right)$, which are better than their original solutions for next generation $\left(G_{k+1}\right)$, as shown in (11) and (12). However, the GA might be trapped in local minima or local maxima that required a special operation to take it out. Thus, the mutation operation is the operation that will do this task as shown in (13) and (14), where $\gamma$ and $\sigma$ are random numbers between 0 and 1.

$$
\begin{gathered}
X_{m d}=X_{m}+\gamma\left(X_{m}-X_{n}\right) \\
X_{n d}=X_{n}+\gamma\left(X_{n}-X_{m}\right) \\
X_{m d}=X_{m d}+\sigma\left(X^{\max }-X^{\min }\right) \\
X_{n d}=X_{n d}+\sigma\left(X^{\max }-X^{\min }\right) .
\end{gathered}
$$

Several GA approaches have been utilized in recent studies such as $[7,15,29]$. It indicates and highlights the high effectiveness of the GA compared to other stochastic approaches that are based on the error percentage of the solution and the processing duration. Figure 5 illustrates the utilization of GA to find the optimal allocation of BESS.

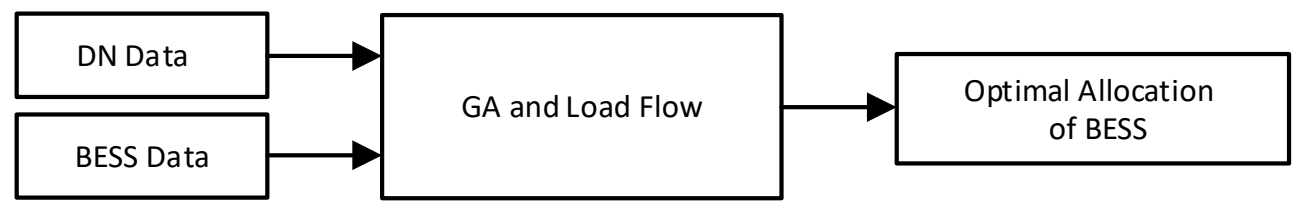

Figure 5. Illustration of GA utilization to find BESS optimal allocation.

In this study, the DN data and the BESSs data are fed as inputs to the GA. The input data has been processed through many iterations and GA internal operations. The resultant of the GA processing is the optimal locations of the BESSs in the DN which assure the minimum average power losses.

\section{Results and Discussions}

To validate the proposed technique in this paper, the IEEE 33-Bus system has been utilized as a case study and incorporated the provided data in [33]. The system is linked with the utility grid via a transmission line with limited capacity. The presented work contains four cases that have been simulated using MATLAB software. The focus of this work was the total power losses reduction in DN. Starting with the reference case study, which is used to compare the improvements before and after the addition of the solar PV systems, an aggregated BESS or distributed BESSs. Hence, the reference case demonstrates the DN with no solar PV systems and BESS. This case is used as a reference while comparing the total power losses reduction in all considered cases. Then Case-I considers only PVs in place. After that, Case-II includes solar PVs and an aggregated BESS. Finally, Case-III comprises solar PVs and distributed BESSs. A detailed description of each case is presented as per the following subsections: 


\subsection{Distribution System with Solar PVs: Case-I}

Six solar PVs, each with a size of $1.6 \mathrm{~kW}$, are added arbitrary in the distribution network, as shown in Figure 6. This case demonstrates DN with a high level of PV penetration. The PVs are installed on buses $3,8,14,25,30$, and 31 .

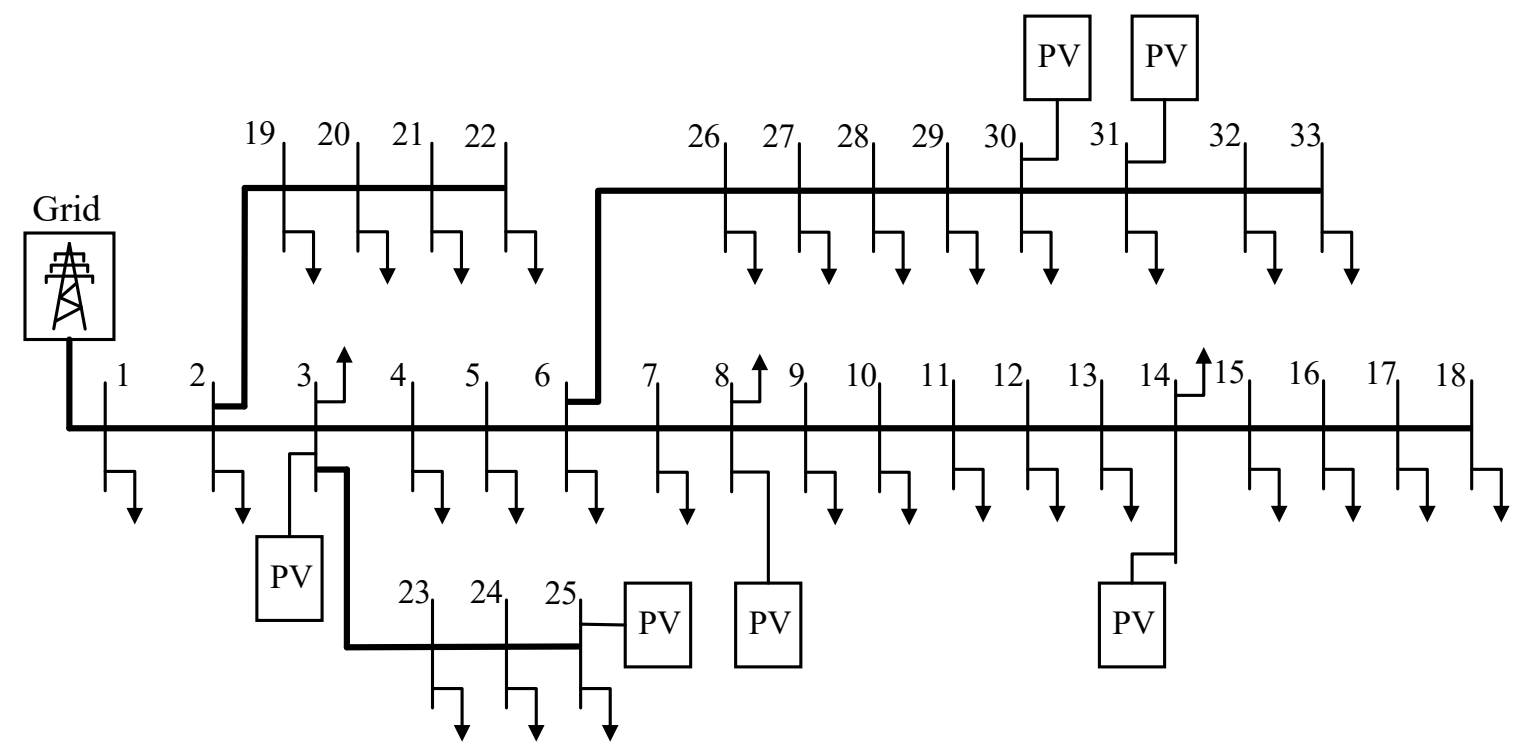

Figure 6. IEEE 33-Bus with solar PVs.

Figures 7 and 8 show the system load profile for a one day selected from the winter season as minimum and another day from summer season as maximum, respectively. The actual load profile of Dammam city (Saudi Arabia) on 2 January 2019, is recorded as the minimum daily load profile throughout the year 2019, as shown in Figure 7. During the selected minimum daily load profile, the load varies from $6300 \mathrm{~kW}$ at 08:00 to reach to $7400 \mathrm{~kW}$ at 19:00. On the other hand, the actual load profile of Dammam city (Saudi Arabia) on 5 September 2019, is documented as the maximum daily load profile of 2019, as shown in Figure 8. During the selected maximum daily load profile, the load varies from $6500 \mathrm{~kW}$ at 07:00 to $7400 \mathrm{~kW}$ at 14:00.

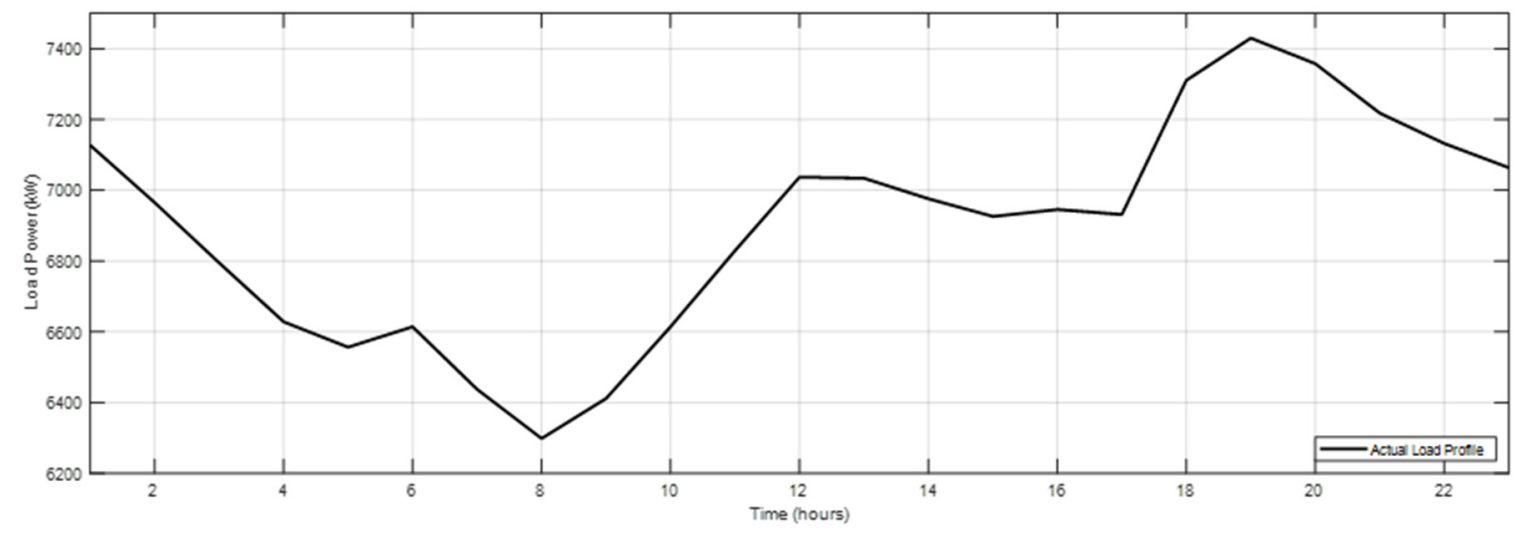

Figure 7. Minimum daily load profile in Dammam city. 


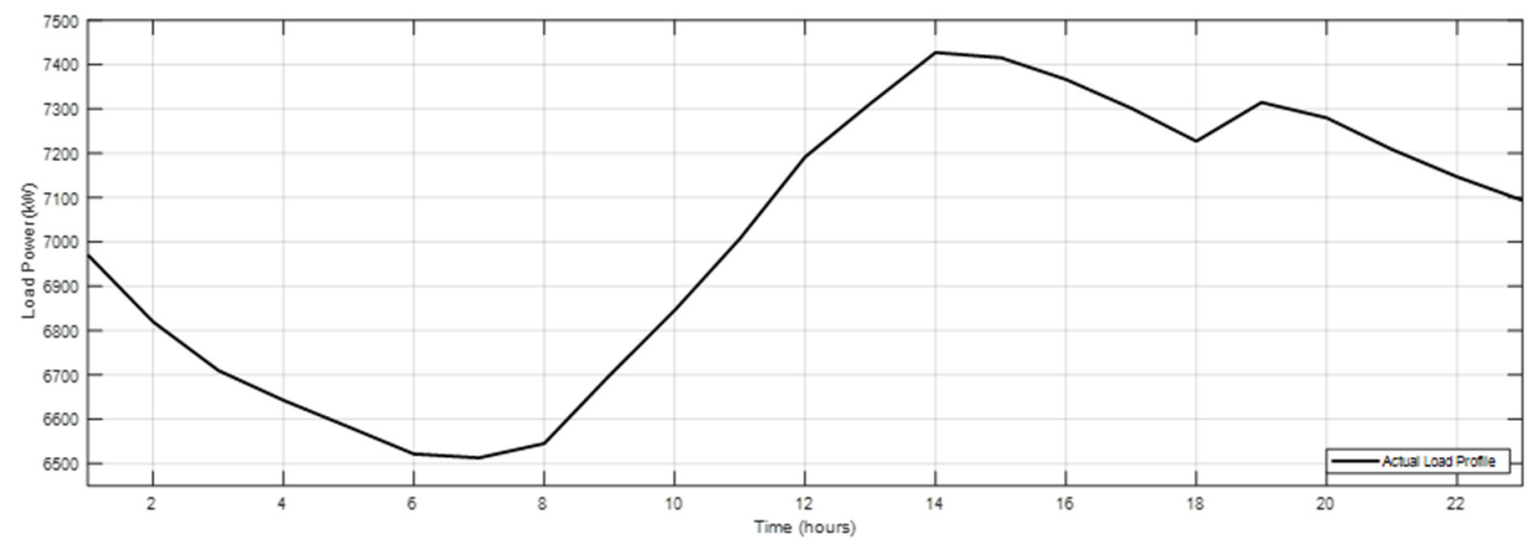

Figure 8. Maximum daily load profile in Dammam city.

From the contrast of Figure 4 against Figure 7 as well as Figure 8, it can be noticed that the PV model has a maximum output power that is not corresponding to the maximum load profile. Apparently, this mismatch leads to a huge limitation on the penetration magnitude as of which PV can supply power to DN. One of the promising solutions for this limitation is to utilize the ESS solution such as BESS. With the use of BESS, it is possible to store power when demand is low and then supply power back when demand is high. Nevertheless, the BESS is a key enabler for proper management of load leveling including DNs.

\subsection{Distribution System with Solar PVs and an Aggregated BESS: Case-II}

Aggregated BESSs are widely used in DNs for ancillary services. However, the BESS proper allocation plays a significant role in maximizing the benefits from aggregated BESS installment. Hence, GA optimization technique is used to optimally allocate the aggregated BESS within the considered IEEE 33-Bus system, as shown in Figure 9.

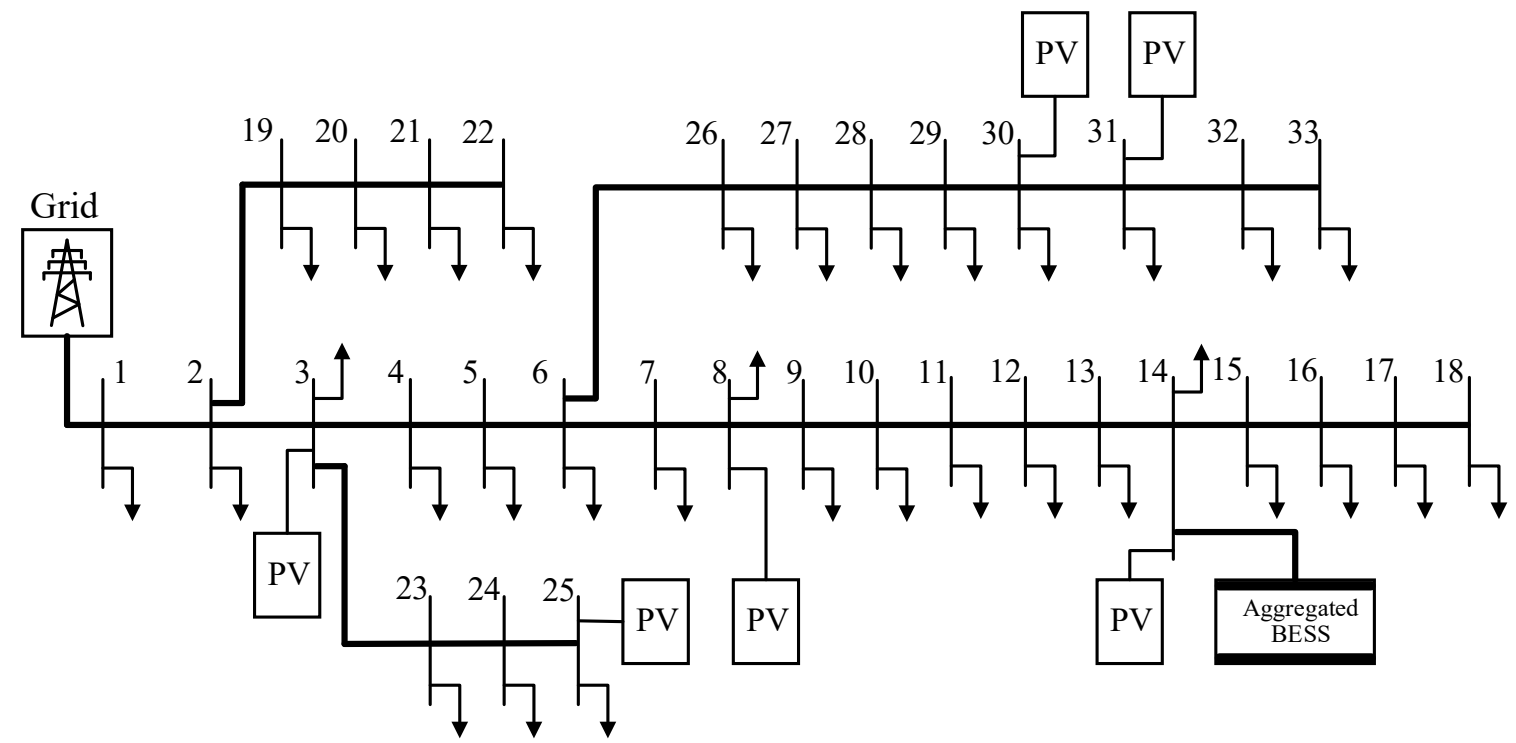

Figure 9. IEEE 33-Bus with PV and Aggregated BESS.

As shown above, there are six solar PV systems installed in the following buses 3, 8, 14, 25, 30 and 31. The placement of PVs has been carried out in a similar manner as of case-I. However, with the utilization of GA, the aggregated BESS is optimally allocated and installed on bus 14 . The size of the aggregated BESS is $0.7 \mathrm{kWh}$. Figures 10 and 11 demonstrate the system load profile comparison with and without an aggregated BESS. It can be observed in Figure 10 that the demanded load has been 
leveled up at $6900 \mathrm{~kW}$ from 02:00 to 10:00. In addition, the demanded load has been leveled down at $7100 \mathrm{~kW}$ from 17:00 to 21:00. Similarly, it can be seen in Figure 11 that the demanded load has been leveled up at $7000 \mathrm{~kW}$ from 00:00 to 10:00. Also, the demanded load has been leveled down at $7200 \mathrm{~kW}$ from 11:00 to 20:00. Overall, the load profile with BESS provides flexibility for the system operators and increases the utilization factor of the solar PVs.

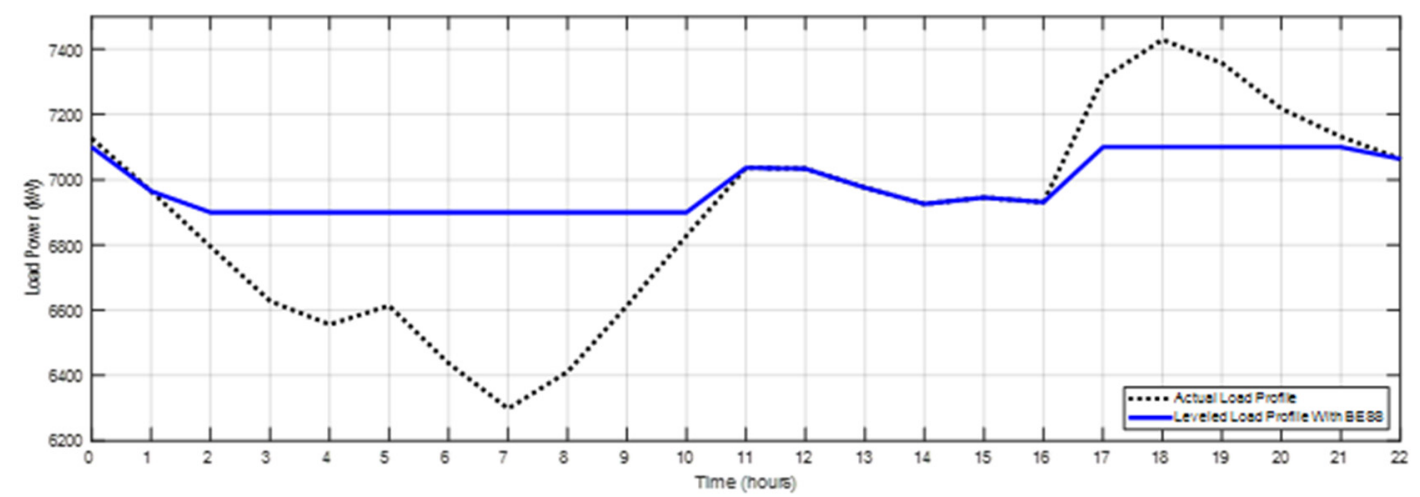

Figure 10. Aggregated Case: Minimum System load profile with/without BESS.

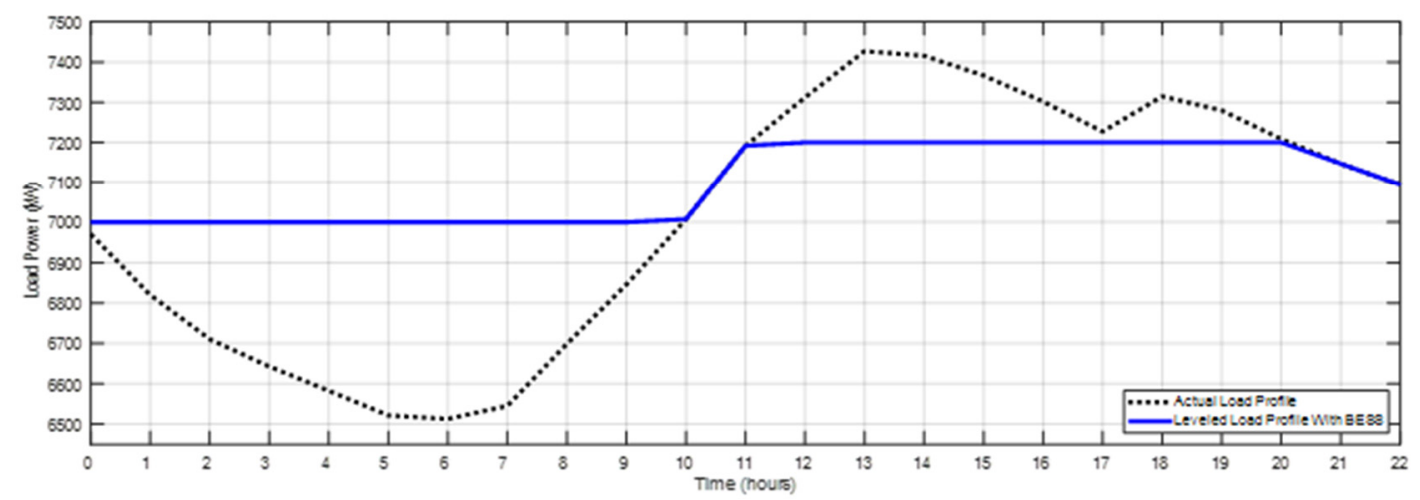

Figure 11. Aggregated Case: Maximum System load profile with/without BESS.

\subsection{Distribution System with Solar PVs and Distributed BESSs: Case-III}

The case-III shows the DN with a high level of PV penetration along with distributed BESSs. It is represented in the IEEE 33-Bus with PV and distributed BESSs, as shown in Figure 12. Similarly, the GA optimization technique is used to optimally allocate the distributed BESSs within the considered system. As shown below, there are six solar PV systems installed in the following buses 3, 8, 14, 25, 30 and 31. The placement of PVs has been carried out in a similar manner as of case-I. Whereas, the six distributed BESSs are optimally allocated and connected to the following buses 8, 14, 24, 25, 30, and 31 . The size of each distributed BESS is $0.11 \mathrm{kWh}$, which is almost one sixth times the aggregated BESS. 


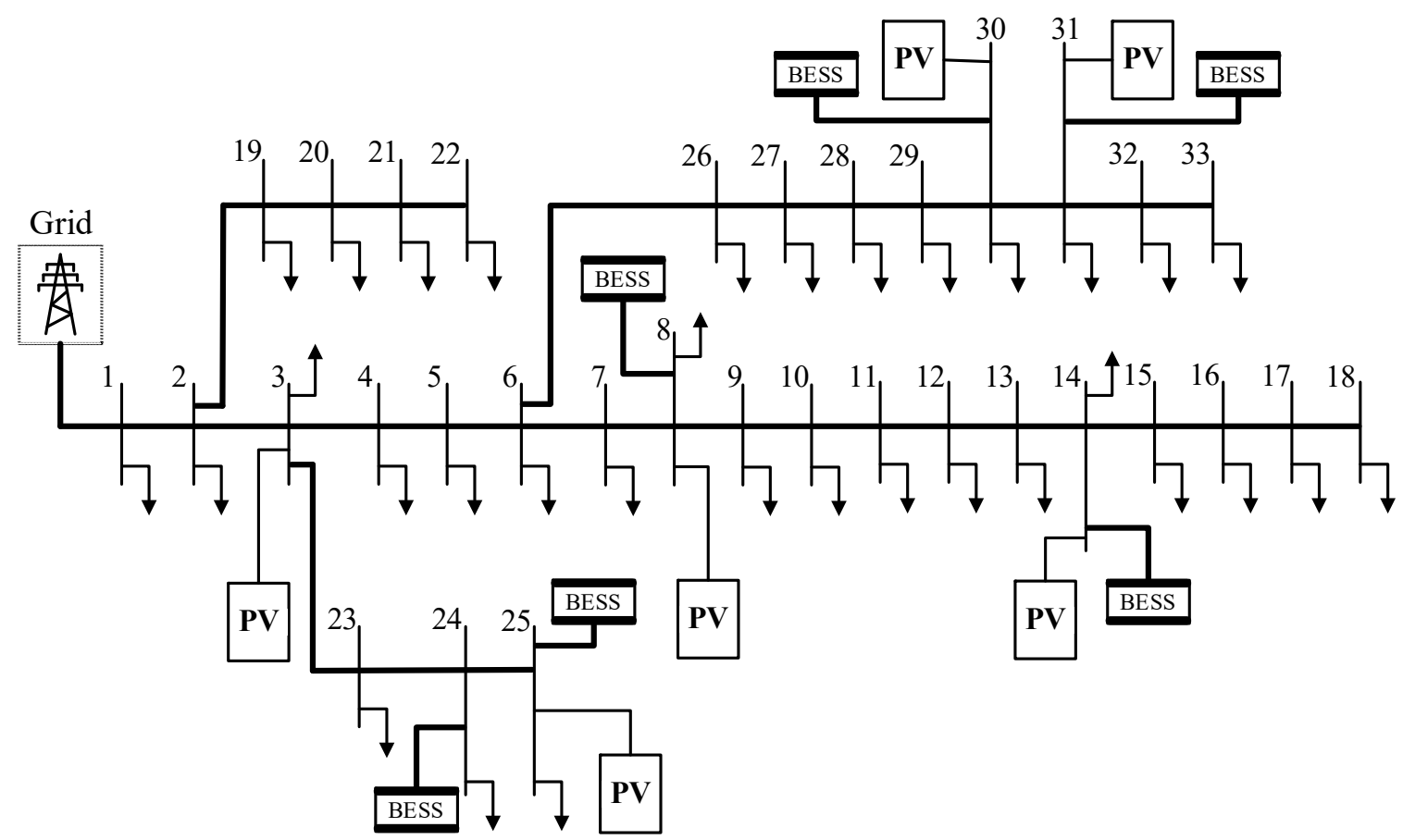

Figure 12. IEEE 33-Bus with PV and distributed BESS.

In contrast, Figures 13 and 14 represent an individual bus load with a single distributed BESS and a single PV system. By considering one day duration, the charging of the BESSs starts during the low demand period and discharging the stored energies back during the high demand period. It can be observed in Figure 13 that the demanded load has been leveled up at $222 \mathrm{~kW}$ from 02:00 to 10:00. Moreover, the demanded load has been leveled down at $230 \mathrm{~kW}$ from 17:00 to 21:00. Likewise, it can be seen in Figure 14 that the demanded load has been leveled up at $222 \mathrm{~kW}$ from 01:00 to 09:00. In contrast, the demanded load has been leveled down at $230 \mathrm{~kW}$ from 11:00 to 21:00. The presented load profiles with distributed BESSs provide more flexibility for the system operators as it reduces the power flow within the DN. Besides, it helps to increase the solar PVs' utilization factor.

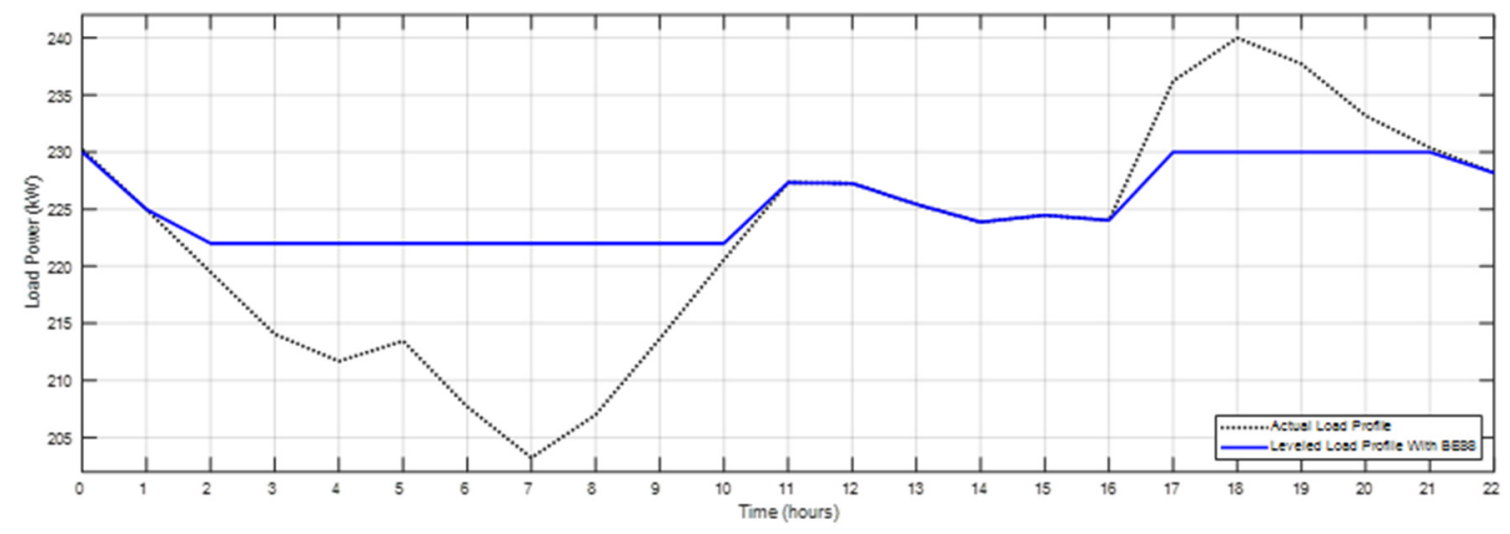

Figure 13. Distributed Case: Minimum Individual Bus-load profile with/without a BESS. 


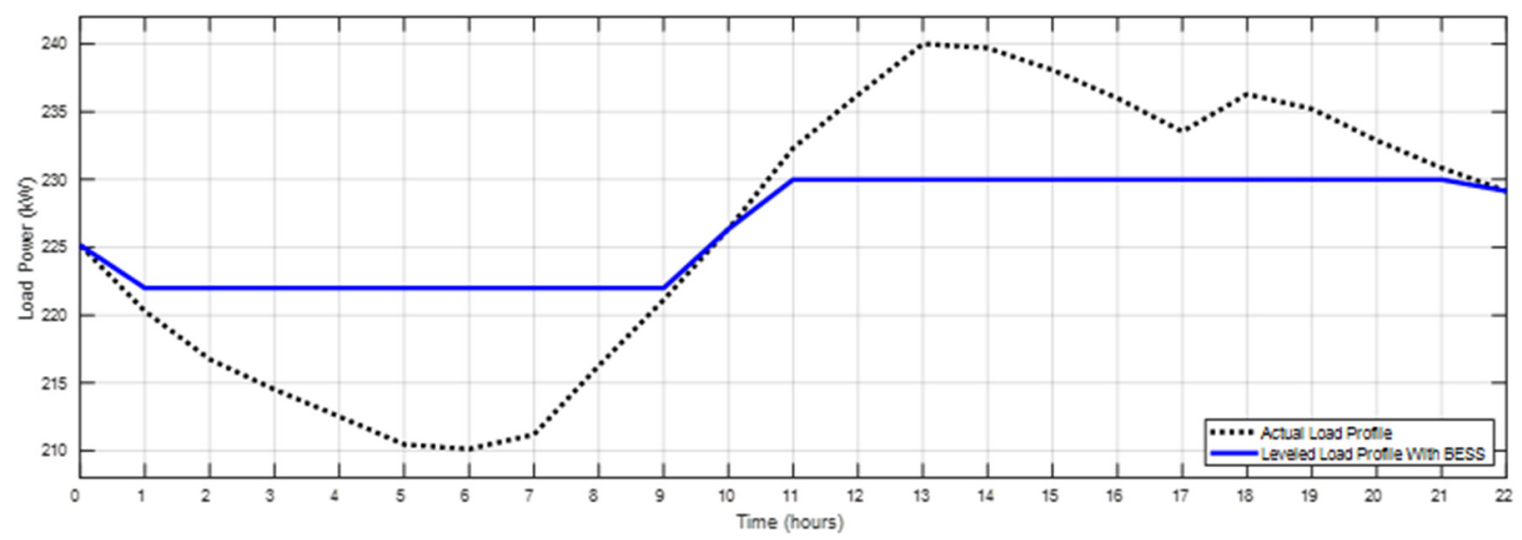

Figure 14. Distributed Case: Maximum Individual Bus-load profile with/without a BESS.

The use of BESS helps to achieve huge improvements in energy management through the practice of load leveling, as demonstrated in Figures 10,11, 13 and 14. It can be seen that the demand valley has been filled during the low demand period and power was injected during the high demand period. Hence, the generated power from the solar PV systems is now properly utilized. In addition, the numbers of committed generation units are reduced, which provides the DN with more flexibility. Hence, the necessity for new power generation and transmission lines is minimized. The power losses reductions for the considered cases in this paper are summarized in Table 1.

Table 1. Power losses reduction for the considered cases.

\begin{tabular}{ccccc}
\hline \multirow{2}{*}{ Cases } & \multicolumn{2}{c}{$\begin{array}{c}\text { Average Power } \\
\text { Losses } \mathbf{( k W h )}\end{array}$} & $\begin{array}{c}\text { Average Power } \\
\text { Losses (kWh) }\end{array}$ & $\begin{array}{c}\text { Total Power Losses } \\
\text { Reduction } \mathbf{( \% )}\end{array}$ \\
\cline { 2 - 5 } & Winter & Summer & Annual Average \\
\hline Reference Case (Without PVs and BESS) & 580.24 & 614.80 & 597.52 & 0.00 \\
PVs Case-I & 378.60 & 393.20 & 385.90 & 35.36 \\
PVs and Aggregated BESS Case-II & 349.20 & 361.30 & 355.25 & 40.51 \\
PVs and Distributed BESSs Case-III & 252.10 & 253.50 & 252.80 & 57.68 \\
\hline
\end{tabular}

There are four cases considered in this study as illustrated in Table 1; starting with a reference case that represents the DN without PV systems installation or BESS availability. Then, we consider the case when only solar PV systems are connected to the DN. Next, the optimal allocation of an aggregated BESS case and a distributed BESSs case were considered to investigate the technical feasibility to mitigate DN power losses via BESS. The average power losses between winter and summer are provided in each case in $\mathrm{kWh}$. However, the discussion focuses on the annual average, especially the percentage of the total power losses reduction.

In the PVs Case-I, where only solar PVs are installed in DN, the total power losses in the annual average have been reduced by $35.36 \%$. This substantial amount of total power loss reduction is the result of having less power flow between distribution lines since the power supply is now placed near to load centers. Hence, the installation of solar PVs in DNs is a key solution to reduce DN power losses. In fact, this solution is obviously more viable when combined with the BESS solution. However, the question is which configuration strategy of the BESS (e.g., centralized or decentralized) is more feasible in terms of maximizing the contribution toward DN power losses reduction.

The investigation started with an aggregated BESS along with the six installed solar PV systems in DN named PVs and Aggregated BESS Case-II. This case reduces the average power losses by $40.51 \%$, which illustrates additional improvements in minimizing the load flow between the DN buses. However, the reduced percentage of power losses compared to Case-I is only $5.15 \%$. Therefore, this case study shows improvement in power losses reduction, but the aggregated configuration of BESS has a relatively insignificant contribution to the total power losses reduction. 
On the other hand, in the PVs and Distributed BESSs Case-III, six distributed BESSs are installed in the DN along with six solar PV systems. The distributed configuration of BESSs has resulted in a $57.68 \%$ reduction of the $\mathrm{DN}$ average power losses. The power losses reduction is also due to minimizing the load flow between the DN buses which in turn reduces power losses in the DN. Case-III provides the highest percentage of power losses reduction with an improvement of $17.17 \%$ when compared to Case-II, and $22.32 \%$ when compared to Case-I.

After the conducted case studies, Case-I with only solar PV systems showed promising performance in reducing the DN power losses; in Case-II with the addition of an aggregated BESS a slight improvement has been noticed. Clearly, the highest attained reduction of the total power losses is found to be in Case-III with the distributed BESSs configuration combined with solar PV systems.

\section{Conclusions}

This study outlines the contribution of high PV penetration towards system losses in a distributed power network and its potential mitigation based on optimal placement of battery energy storage systems (BESS). Accordingly, an optimization technique based on a genetic algorithm has been proposed to effectively establish an optimal BESS placement to significantly reduce the overall system losses associated with the integration of a high penetration level of solar photovoltaics. The effectiveness and robustness of the proposed methodology has been comparatively tested and validated on numerous scenarios induced on the IEEE 33 bus system. Furthermore, a quantitative comparison between aggregated and distributed configuration of BESS installation is studied. The results obtained validates a significant reduction in system losses with $40.51 \%$ and $57.68 \%$ reduction in aggregated and distributed BESS scenarios, respectively. The future potential of this study consists of potential increments in PV penetration that can be achieved with the proposed optimization technique and the associated operational study on the impact in distribution networks is a crucial contribution in the field of renewable integration.

Author Contributions: Conceptualization, H.A., A.A. and M.K.; methodology, H.A., A.A. and M.K.; software, H.A. and A.A.; validation, H.A. and A.A.; formal analysis, H.A., A.A. and M.K.; investigation, H.A., A.A. and M.K.; resources, M.K.; data curation, H.A. and A.A.; writing-original draft preparation, H.A., A.A. and M.K.; writing-review and editing, H.A., A.A. and M.K.; visualization, H.A. and A.A.; supervision, M.K.; project administration, H.A., A.A. and M.K.; funding acquisition, M.K. All authors have read and agreed to the published version of the manuscript.

Funding: The authors would like to acknowledge the support provided by the Deanship of Research (DSR) at King Fahd University of Petroleum \& Minerals (KFUPM) for funding this work through project No. RG171009. In addition, we would like to acknowledge the funding support provided by the King Abdullah City for Atomic and Renewable Energy (K.A. CARE).

Acknowledgments: We would like to thank the Operation and Control Department at National Grid-SA for facilitating the required data to complete this study.

Conflicts of Interest: The authors declare no conflict of interest.

\section{References}

1. Dominguez, O.D.M.; Kasmaei, M.P.; Lavorato, M.; Mantovani, J.R.S. Optimal siting and sizing of renewable energy sources, storage devices, and reactive support devices to obtain a sustainable electrical distribution systems. Energy Syst. 2018, 9, 529-550. [CrossRef]

2. Qiu, J.; Xu, Z.; Zheng, Y.; Wang, N.; Dong, Z.Y. Distributed generation and energy storage system planning for a distribution system operator. IET Renew. Power Gener. 2018, 12, 1345-1353. [CrossRef]

3. Konishi, R.; Takenobu, Y.; Takahashi, M.; Hayashi, Y. Optimal allocation of photovoltaic systems and energy storage systems considering constraints of both transmission and distribution systems. In Proceedings of the 2017 IEEE Power \& Energy Society Innovative Smart Grid Technologies Conference (ISGT), Washington, DC, USA, 23-26 April 2017; pp. 1-5. 
4. AlShehri, J.; Alzahrani, A.; Khalid, M. Wind Energy Conversion Systems and Artificial Neural Networks: Role and Applications. In Proceedings of the 2019 IEEE Innovative Smart Grid Technologies-Asia (ISGT Asia), Chengdu, China, 21-24 May 2019; pp. 1777-1782.

5. Duan, S.; Hu, G.; Chen, C.; Cai, T.; Liu, B. Optimal Allocation and Economic Analysis of Energy Storage System in Microgrids. IEEE Trans. Power Electron. 2011, 26, 2762-2773.

6. Korpaas, M.; Holen, A.T.; Hildrum, R. Operation and sizing of energy storage for wind power plants in a market system. Int. J. Electr. Power Energy Syst. 2003, 25, 599-606. [CrossRef]

7. Awad, A.S.A.; El-Fouly, T.H.M.; Salama, M.M.A. Optimal ESS Allocation for Benefit Maximization in Distribution Networks. IEEE Trans. Smart Grid 2015, 8, 1668-1678. [CrossRef]

8. Lei, J.; Gong, Q. Optimal allocation of a hybrid energy storage system considering its dynamic operation characteristics for wind power applications in active distribution networks. Int. J. Energy Res. 2018, 42, 4184-4196. [CrossRef]

9. Zhang, Y.; Meng, K.; Luo, F.; Dong, Z.Y.; Wong, K.P.; Zheng, Y. Optimal allocation of battery energy storage systems in distribution networks with high wind power penetration. IET Renew. Power Gener. 2016, 10, 1105-1113. [CrossRef]

10. Atwa, Y.M.; El-Saadany, E.F. Optimal Allocation of ESS in Distribution Systems With a High Penetration of Wind Energy. IEEE Trans. Power Syst. 2010, 25, 1815-1822. [CrossRef]

11. Akram, U.; Khalid, M. A coordinated frequency regulation framework based on hybrid battery-ultracapacitor energy storage technologies. IEEE Access 2017, 6, 7310-7320. [CrossRef]

12. Gabdullin, Y.; Azzopardi, B. Impacts of High Penetration of Photovoltaic Integration in Malta. In Proceedings of the 2018 IEEE 7th World Conference on Photovoltaic Energy Conversion (WCPEC) (A Joint Conference of 45th IEEE PVSC, 28th PVSEC \& 34th EU PVSEC), Waikoloa Village, HI, USA, 10-15 June 2018; pp. 1398-1401.

13. Khalid, M.; Akram, U.; Shafiq, S. Optimal Planning of Multiple Distributed Generating Units and Storage in Active Distribution Networks. IEEE Access 2018, 6, 55234-55244. [CrossRef]

14. AlShehri, J.; Khalid, M.; Alzahrani, A. An Intelligent Battery Energy Storage-Based Controller for Power Quality Improvement in Microgrids. Energies 2019, 12, 2112. [CrossRef]

15. Awad, A.S.A.; El-Fouly, T.H.M.; Salama, M.M.A. Optimal ESS Allocation and Load Shedding for Improving Distribution System Reliability. IEEE Trans. Smart Grid 2014, 5, 2339-2349. [CrossRef]

16. Lan, H.; Yin, H.; Wen, S.; Hong, Y.-Y.; Yu, D.C.; Zhang, L. Electrical Energy Forecasting and Optimal Allocation of ESS in a Hybrid Wind-Diesel Power System. Appl. Sci. 2017, 7, 155. [CrossRef]

17. Wen, S.; Lan, H.; Fu, Q.; Yu, D.C.; Hong, Y.-Y.; Cheng, P. Optimal Allocation of Energy Storage System Considering Multi-Correlated Wind Farms. Energies 2017, 10, 625. [CrossRef]

18. Das, C.K.; Bass, O.; Kothapalli, G.; Mahmoud, T.S.; Habibi, D. Optimal placement of distributed energy storage systems in distribution networks using artificial bee colony algorithm. Appl. Energy 2018, 232, 212-228. [CrossRef]

19. Zheng, L.; Hu, W.; Lu, Q.; Min, Y. Optimal energy storage system allocation and operation for improving wind power penetration. IET Gener. Transm. Distrib. 2015, 9, 2672-2678. [CrossRef]

20. Das, C.K.; Bass, O.; Kothapalli, G.; Mahmoud, T.S.; Habibi, D. Overview of energy storage systems in distribution networks: Placement, sizing, operation, and power quality. Renew. Sustain. Energy Rev. 2018, 91, 1205-1230. [CrossRef]

21. Abdulgalil, M.A.; Khalid, M.; AlShehri, J. Microgrid Reliability Evaluation Using Distributed Energy Storage Systems. In Proceedings of the 2019 IEEE Innovative Smart Grid Technologies-Asia (ISGT Asia), Chengdu, China, 21-24 May 2019; pp. 2837-2841.

22. Akram, U.; Khalid, M.; Shafiq, S. An Innovative Hybrid Wind-Solar and Battery-Supercapacitor Microgrid System-Development and Optimization. IEEE Access 2017, 5, 25897-25912. [CrossRef]

23. Awad, A.S.A.; El-Fouly, T.H.M.; Salama, M.M.A. Optimal ESS Allocation for Load Management Application. IEEE Trans. Power Syst. 2014, 30, 327-336. [CrossRef]

24. Qin, M.; Chan, K.W.; Luo, X.; Wu, T.; Chung, C.Y. Optimal planning and operation of energy storage systems in radial networks for wind power integration with reserve support. IET Gener. Transm. Distrib. 2016, 10, 2019-2025. [CrossRef]

25. Zheng, Y.; Dong, Z.Y.; Luo, F.J.; Meng, K.; Qiu, J.; Wong, K.P. Optimal Allocation of Energy Storage System for Risk Mitigation of DISCOs With High Renewable Penetrations. IEEE Trans. Power Syst. 2013, 29, $212-220$. [CrossRef] 
26. Raptis, D.A.; Periandros, P.S.; Gkaidatzis, P.A.; Bouhouras, A.S.; Labridis, D.P. Optimal Siting of BESS in Distribution Networks under High PV Penetration. In Proceedings of the 2018 53rd International Universities Power Engineering Conference (UPEC), Glasgow, UK, 4-7 September 2018; pp. 1-6.

27. Ashtiani, N.A.; Gholami, M.; Gharehpetian, G.B. Optimal allocation of energy storage systems in connected microgrid to minimize the energy cost. In Proceedings of the 2014 19th Conference on Electrical Power Distribution Networks (EPDC), Tehran, Iran, 6-7 May 2014; pp. 25-28.

28. Zidar, M.; Hatziargyriou, N.D.; Škrlec, D.; Capuder, T.; Georgilakis, P.S. Review of energy storage allocation in power distribution networks: Applications, methods and future research. IET Gener. Transm. Distrib. 2016, 10, 645-652. [CrossRef]

29. Rangel, C.A.S.; Canha, L.; Sperandio, M.; Severiano, R. Methodology for ESS-type selection and optimal energy management in distribution system with DG considering reverse flow limitations and cost penalties. IET Gener. Transm. Distrib. 2017, 12, 1164-1170. [CrossRef]

30. Giannitrapani, A.; Paoletti, S.; Vicino, A.; Zarrilli, D. Optimal allocation of energy storage systems for voltage control in LV distribution networks. IEEE Trans. Smart Grid 2016, 8, 2859-2870. [CrossRef]

31. Quan, H.; Li, B.; Xiu, X.; Hui, D. Impact analysis for high-penetration distributed photovoltaic generation integrated into grid based on DIgSILENT. In Proceedings of the 2017 IEEE Conference on Energy Internet and Energy System Integration (EI2), Beijing, China, 26-28 November 2017; pp. 1-6.

32. Zhang, L.; Zhou, Y.; Flynn, D.; Mutale, J.; Mancarella, P. System-Level Operational and Adequacy Impact Assessment of Photovoltaic and Distributed Energy Storage, with Consideration of Inertial Constraints, Dynamic Reserve and Interconnection Flexibility. Energies 2017, 10, 989. [CrossRef]

33. Venkatesh, B.; Ranjan, R. Optimal radial distribution system reconfiguration using fuzzy adaptation of evolutionary programming. Int. J. Electr. Power Energy Syst. 2003, 25, 775-780. [CrossRef]

34. Faessler, B.; Schuler, M.; Preißinger, M.; Kepplinger, P. Battery Storage Systems as Grid-Balancing Measure in Low-Voltage Distribution Grids with Distributed Generation. Energies 2017, 10, 2161. [CrossRef]

35. Atia, R.; Yamada, N. Distributed Renewable Generation and Storage System Sizing Based on Smart Dispatch of Microgrids. Energies 2016, 9, 176. [CrossRef]

36. Nourai, A.; Kogan, V.; Schafer, C. Load Leveling Reduces T\&D Line Losses. IEEE Trans. Power Deliv. 2008, 23, 2168-2173.

37. Mokhtari, G.; Nourbakhsh, G.; Ledwich, G.; Ghosh, A. A Supervisory Load-Leveling Approach to Improve the Voltage Profile in Distribution Network. IEEE Trans. Sustain. Energy 2014, 6, 245-252. [CrossRef]

38. Pozo, D.; Contreras, J.; Sauma, E.E. Unit Commitment With Ideal and Generic Energy Storage Units. IEEE Trans. Power Syst. 2014, 29, 2974-2984. [CrossRef]

39. Grygierek, K.; Ferdyn-Grygierek, J. Multi-Objective Optimization of the Envelope of Building with Natural Ventilation. Energies 2018, 11, 1383. [CrossRef]

40. Mi, Z.; Jia, Y.; Wang, J.; Zheng, X. Optimal Scheduling Strategies of Distributed Energy Storage Aggregator in Energy and Reserve Markets Considering Wind Power Uncertainties. Energies 2018, 11, 1242. [CrossRef] 